\title{
Structural, optical, thermal and NLO behavior of zinc hydrogen maleate dihydrate single crystal
}

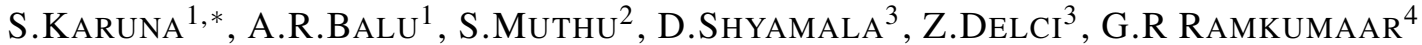 \\ ${ }^{1}$ Department of Physics, A.V.V.M Sri Pushpam College, Thanjavur 613 503, India \\ ${ }^{2}$ Department of Physics, Arignar Anna Govt Arts college Cheyyar 604 407, India \\ ${ }^{3}$ Department of Physics, D.G.Vaishnav College, Chennai 600 106, India \\ ${ }^{4}$ Department of Physics, Kandaswami College for Men, Anna Nagar East, Chennai
}

\begin{abstract}
Single crystal of zinc hydrogen maleate dihydrate (ZHMD) is grown by slow evaporation method at room temperature. The compound crystallizes in triclinic system with noncentrosymmetric space group P1. FT-IR and FT-Raman spectra of ZHMD are recorded. The versatile DFT is employed to understand the band structure of the crystal. Dipole moment of the molecule, ionization energy and electron affinity are established. The potential energy distribution PED of the vibrational modes is calculated using VEDA4. The results of the optimized molecular structure are compared with the single crystal XRD data. The Mulliken and NBO charges are calculated and interpreted. Optical properties of the grown crystal are analyzed using UV-Vis spectrum. Energy gap determined by Tauc plot is in a good agreement with the theoretical value calculated from HOMO-LUMO energies. Thermogravimetric analysis is done to assess the thermal behavior of the ZHMD crystal. Various thermodynamic parameters are calculated using the basis set B3LYP. The first order hyperpolarizability values of ZHMD establish its NLO nature. The molecular electrostatic potential MEP of the molecule is obtained. Third-order nonlinear response is studied using Z-scan technique and the corresponding parameters such as absorption coefficient, refractive index and third-order susceptibility are determined.
\end{abstract}

Keywords: ZHMD; UV-Vis; Tauc plot; DFT, enthalpy; Z-scan

\section{Introduction}

In the recent past, considerable attempt has been made to combine a metal ion with interesting organic and inorganic matrices to produce NLO materials with desirable properties. A metalorganic compound consists of metal or metal cluster centers that are connected by multidentate organic ligands. The interest in this class of compounds stems not only from the structural diversity they display but predominately due to their potential applicability as NLO materials. Zinc based single crystals possess a wide range of applications in the field of telecommunication and optical information storage devices. Zinc acetate dihydrate belongs to the family of inorganic nonlinear optical crystal. Maleic acid with relatively large

*E-mail: skaruna2013@gmail.com $\pi$-conjugation has attracted attention of crystal growers. Maleic acid forms crystalline maleate of various organic molecules through hydrogen bonding and $\pi-\pi$ interactions and the intramolecular hydrogen bond in maleic acid is very strong $[1,2]$. Maleic acid acts not only as an acceptor but also as an acidic ligand. It is reported that compounds of maleate such as L-arginine maleate dehydrate, L-phenylalaninium maleate, L-alaninium maleate and 2 aminopyridinium maleate dihydrate have improved NLO efficiency [3-5]. Maleates are of practical importance because they are efficient catalysts and also have medical significance. Recently, synthesis of ZHMD and its properties have been reported [6]. The hydrogen maleate ion has been studied by ab initio method [7]. In the present work, the influence of zinc on electron correlation and thereby hydrogen bonding in the crystal is investigated by DFT calculations. The results are reported for the first time. 


\section{Experimental}

ZHMD is synthesized by taking analytical grade chemicals of zinc acetate dihydrate and maleic acid in 1:1 ratio. The chemicals are dissolved in double distilled water. The prepared mixture is stirred well for 10 hours using a motorized magnetic stirrer at room temperature and a clear solution is obtained. The synthesized material is purified by repeated recrystallization process. Slow evaporation of the solvent yields small transparent, defect free crystals, optically clear and perfectly shaped. The crystals are obtained in a growth period of 6 days. The dimensions of the grown crystal are $0.5 \mathrm{~cm} \times 0.5 \mathrm{~cm} \times 0.2 \mathrm{~cm}$. The photograph of the grown crystal is shown in Fig. 1. The grown ZHMD crystal is subjected to various characterization studies. FT-IR and FT-Raman spectra of ZHMD are recorded in the range of $4000 \mathrm{~cm}^{-1}$ to $400 \mathrm{~cm}^{-1}$ on Bruker IFS $66 \mathrm{~V}$ spectrometer using $\mathrm{KBr}$ pellet technique. A Bruker kappa ApexII single crystal X-ray diffractometer with $\operatorname{MoK} \alpha$ $(\lambda=0.71073 \AA)$ radiation is used to obtain the structure of ZHMD crystal. The optical transmission spectrum of the crystal is recorded in the region of $200 \mathrm{~nm}$ to $800 \mathrm{~nm}$, using a Varian/Cary 5000 UV-Vis-NIR spectrophotometer. The thermal behavior of the crystal has been investigated using PerkinElmer thermal analyzer at Department of Chemistry, IIT Madras. The third order nonlinearity of the grown crystal is studied using the Z-scan technique. The studies have been carried out at NIT Trichy.

\section{Computational details}

The entire quantum chemical calculations are performed by DFT (B3LYP) method of $6-311++\mathrm{G}(\mathrm{d}, \mathrm{p})$ using the Gaussian 03W program. No imaginary frequencies are observed assuming that optimized geometry is obtained. The bond length and bond angles obtained from single crystal XRD are used to determine reduced masses, force constants, infrared intensities band assignment, Raman activities and depolarization ratio [8]. The vibrational modes are confirmed using Vibrational Energy Distribution Analysis VEDA program [9].

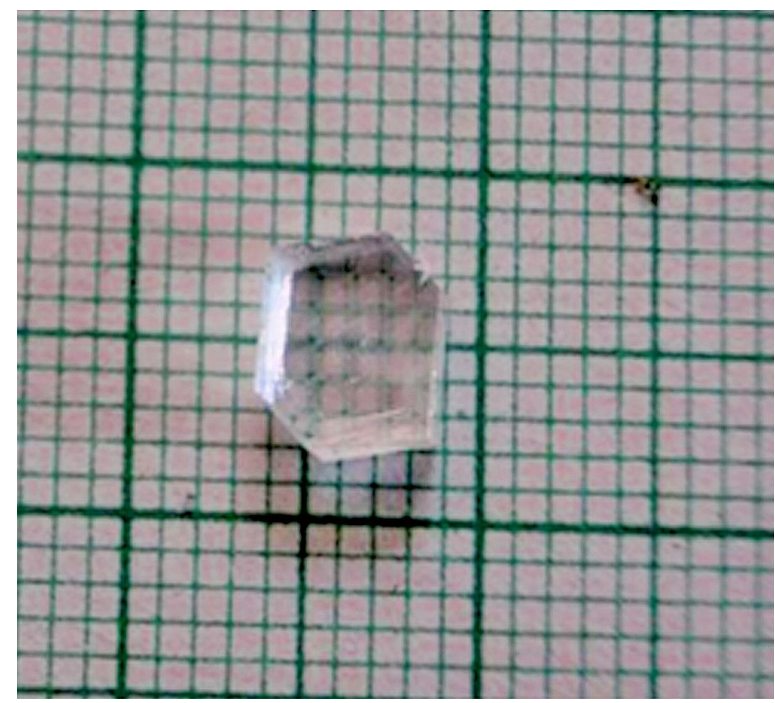

Fig. 1. Photograph of the as grown ZHMD crystal.

The assignments of the calculated wavenumbers are made on the basis of the Gaussview program [10]. On the basis of the optimized ground state geometries, TD-DFT calculation is performed at the same level of accuracy to investigate the absorption and electronic properties of ZHMD crystal. The excitation energy and oscillator strength are discussed using 6-311++G (d,p) basis set [11, 12]. The natural bond orbital (NBO) calculation $[13,14]$ is performed using NBO3.1 program contained in the Gaussian W03 package in order to understand various second order interactions which are a measure of intermolecular and intramolecular delocalizations.

\section{Results and discussion}

\subsection{Molecular geometry}

The crystal data obtained from single crystal XRD are given in Table 1. The optimized structural parameters of ZHMD calculated by B3LYP method with 6-311++G(d,p) basis set are listed in Table 2. The optimized structure is compared with experimental data. The ORTEP and optimized molecular structure of the title molecule along with the numbering of atoms in the scheme is given in Fig. 2 and Fig. 3, respectively. The theoretical values of bond lengths and bond 
angles calculated using 6-311++G(d,p) basis set are found to slightly differ with respect to the experimental values obtained for single crystal XRD. This is due to the fact that probably the theoretical calculations are done assuming an isolated molecule in gaseous phase whereas the experimental results apply to a molecule in solid state [15]. From Table 2 it is seen that the bond $\mathrm{O} 1-\mathrm{Zn}$ has a value of $2.1311 \AA$ which is maximum, while the bond O5-H5 with a value of $0.79815 \AA$ is the least. Thus, it is observed that the bond lengths calculated by B3LYP/6-311++G(d,p) basis set agree well with the experimental values [16-18].

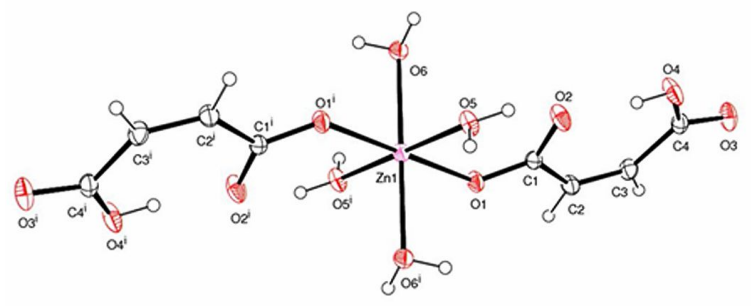

Fig. 2. ORTEP diagram of ZHMD single crystal.

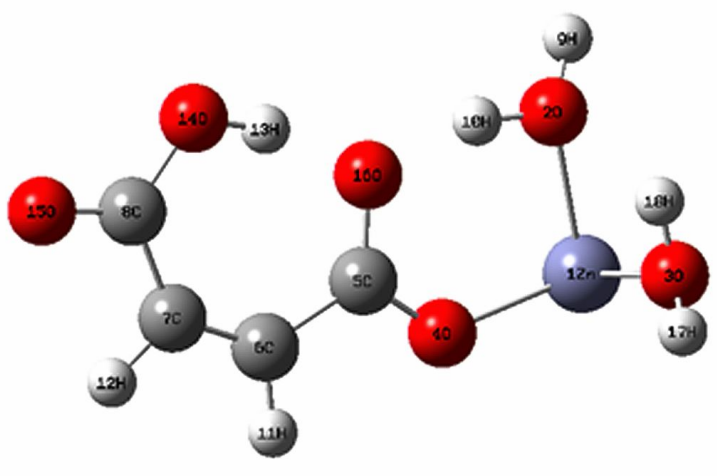

Fig. 3. Optimized molecular structure and atomic numbering of ZHMD single crystal.

\subsection{Vibrational assignments}

The FT-IR spectrum of a compound results due to superposition of absorption bands of specific functional groups. The vibrational band assignment of the molecule is made by observing the position, shape and relative intensities of the bands in FT-IR spectrum. The assignments are summarized in Table 3. The $\mathrm{O}-\mathrm{H}, \mathrm{C}-\mathrm{H}$ and $\mathrm{C}-\mathrm{O}$ stretching vibrations are characteristic with regard to their shape and frequency and generally are observed in the region of $3600 \mathrm{~cm}^{-1}$ to $1700 \mathrm{~cm}^{-1}$. The first feature observed in the vibrational spectrum of ZHMD is the broad band at $3386 \mathrm{~cm}^{-1}$. It is the stretching vibration of the $\mathrm{O}-\mathrm{H}$ bond present in the molecule. The $\mathrm{O}-\mathrm{H}$ stretching vibration generally appears as a broad band extending from $3250 \mathrm{~cm}^{-1}$ to about $3550 \mathrm{~cm}^{-1}$. Its appearance in this region suggests that the $\mathrm{O}-\mathrm{H}$ stretching vibration is influenced by hydrogen bonding $[19,20]$. The ring stretching band appears at $1505 \mathrm{~cm}^{-1}[21,22]$. The absorption band at $1193 \mathrm{~cm}^{-1}$ belongs to the asymmetric stretching vibration of the $\mathrm{C}-\mathrm{O}$ group. The bending vibrations are generally found at lower wave numbers. The bands observed at $714 \mathrm{~cm}^{-1}$ and $573 \mathrm{~cm}^{-1}$ are assigned to $\mathrm{O}-\mathrm{C}-\mathrm{C}, \mathrm{C}-\mathrm{O}-\mathrm{H}$ and $\mathrm{C}-\mathrm{C}-\mathrm{C}$ bending of the ring [23-25]. The bands at $566 \mathrm{~cm}^{-1}$ to $250 \mathrm{~cm}^{-1}$ in the FT-Raman spectrum are due to $\mathrm{C}-\mathrm{H}$ out of plane deformation. The ZHMD molecule consists of 18 atoms, therefore, they have 48 normal modes. All the 48 fundamental vibrations are active in both IR and Raman spectra. The harmonic vibrational frequencies calculated for ZHMD by the B3LYP method using the $6-311++\mathrm{G}(\mathrm{d}, \mathrm{p})$ basis set are listed in Table 3 along with the frequencies as observed in the FT-IR spectrum. The experimental and theoretical FT-IR and FT-Raman spectra of ZHMD are shown in Fig. 4 and Fig. 5.

\subsection{UV-Vis studies}

UV-Vis spectroscopy correlates the electronic excitations between the energy levels that correspond to the molecular orbitals of the system [2628]. UV-Vis spectroscopy is mostly used to identify conjugated systems which tend to have a stronger absorption. The recorded UV-Vis spectrum is shown in Fig. 6. The spectrum shows a lower cut off wavelength at $310 \mathrm{~nm}$ which corresponds well with the theoretical value of $324.45 \mathrm{~nm}$ computed using B3LYP basis given in Table 4 . Fig. 7 presents the pictorial illustration of the frontier molecular orbital and corresponding positive and negative regions. In HOMO, the positive region 
Table 1. Crystal data and structure refinement of ZHMD.

\begin{tabular}{ll}
\hline Crystal data & Data collection \\
\hline \hline Empirical formula & $\mathrm{C}_{4} \mathrm{H}_{7} \mathrm{O}_{6} \mathrm{Zn}$ \\
Formula weight & 367.56 \\
Temperature & $293(2) \mathrm{K}$ \\
Wavelength & $0.71073 \AA$ \\
Crystal system, space group & Triclinic, $\mathrm{P}-1$ \\
Unit cell dimensions & $\mathrm{a}=5.2153(2) \AA$ alpha $=108.7240(10) \mathrm{deg}$. \\
& $\mathrm{b}=7.3036(2) \AA$ beta $=104.6410(10) \mathrm{deg}$. \\
& $\mathrm{c}=9.2014(3) \AA$ gamma $=93.1950(10) \mathrm{deg}$. \\
Volume & $317.555(18) \AA^{3}$ \\
$\mathrm{Z}$ & 1 \\
Calculated density & $1.922 \mathrm{Mg} / \mathrm{m}^{3}$ \\
Absorption coefficient & $2.000 \mathrm{~mm}{ }^{-1}$ \\
F(000) & 188 \\
Crystal size & $0.35 \mathrm{~mm} \times 0.30 \mathrm{~mm} \times 0.25 \mathrm{~mm}$ \\
Theta range for data collection & $2.44^{\circ}$ to $26.00^{\circ}$ \\
Limiting indices & $-6<=\mathrm{h}<=6,-8<=\mathrm{k}<=8,-11<=1<=11$ \\
Reflections collected/unique & $9670 / 1251[\mathrm{R}(\mathrm{int})=0.0183]$ \\
Max. and min. transmission & 0.6397 and 0.5410 \\
Refinement method & Full-matrix least-squares on $\mathrm{F}^{2}$ \\
Goodness-of-fit on $\mathrm{F}^{2}$ & 1.109 \\
Final R indices[I $>2$ sigma(I) $]$ & $\mathrm{R} 1=0.0148, \mathrm{wR} 2=0.0423$ \\
$\mathrm{R}$ indices (all data) & $\mathrm{R} 1=0.0148, \mathrm{wR} 2=0.0423$ \\
Extinction coefficient & $0.089(6)$ \\
Largest diff. peak and hole & $0.266 \mathrm{e} \cdot \mathrm{A}^{-3}$ and $-0.169 \mathrm{e} \cdot \mathrm{A}^{-3}$ \\
\hline
\end{tabular}

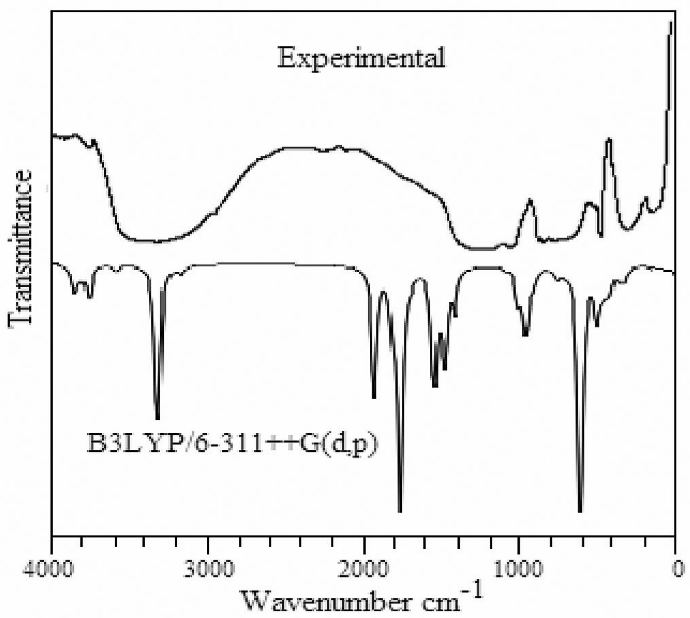

Fig. 4. Experimental and theoretical FT-IR spectra of ZHMD.

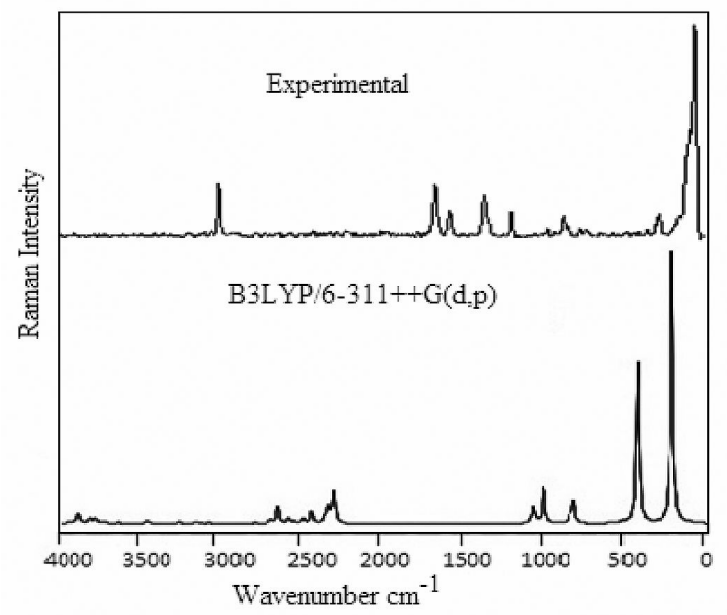

Fig. 5. Experimental and theoretical FT-Raman spectra of ZHMD. 
Table 2. Geometrical parameters optimized in ZHMD by B3LYP with $6-31++\mathrm{G}(\mathrm{d}, \mathrm{p})$ basis set.

\begin{tabular}{|c|c|c|}
\hline Parameter & B3LYP/6-311++G(d,p) & Experimental \\
\hline \multicolumn{3}{|l|}{ Bond length } \\
\hline $\mathrm{C} 1-\mathrm{O} 1$ & 1.264 & 1.251 \\
\hline $\mathrm{C} 1-\mathrm{O} 2$ & 1.274 & 1.26 \\
\hline $\mathrm{C} 1-\mathrm{C} 2$ & 1.481 & 1.489 \\
\hline $\mathrm{C} 2-\mathrm{C} 3$ & 1.347 & 1.332 \\
\hline $\mathrm{C} 2-\mathrm{H} 2$ & 1.082 & 0.93 \\
\hline C3-C4 & 1.496 & 1.487 \\
\hline C3-H3 & 1.083 & 0.93 \\
\hline $\mathrm{C} 4-\mathrm{O} 3$ & 1.238 & 1.222 \\
\hline $\mathrm{C} 4-\mathrm{O} 4$ & 1.352 & 1.288 \\
\hline $\mathrm{O} 1-\mathrm{Zn}$ & 2.058 & 2.131 \\
\hline O5-H5 & 0.866 & 0.798 \\
\hline O4-H4 & 1.007 & 0.82 \\
\hline O5-Zn & 2.156 & 2.035 \\
\hline O6-Zn & 2.102 & 2.12 \\
\hline \multicolumn{3}{|l|}{$\begin{array}{c}\text { Bond angle } \\
\left.{ }^{\circ}{ }^{\circ}\right]\end{array}$} \\
\hline $\mathrm{O} 1-\mathrm{C} 1-\mathrm{O} 2$ & 122.5 & 123 \\
\hline $\mathrm{O} 1-\mathrm{C} 1-\mathrm{C} 2$ & 116.7 & 116.4 \\
\hline $\mathrm{O} 2-\mathrm{C} 1-\mathrm{C} 2$ & 120.8 & 120.6 \\
\hline $\mathrm{C} 3-\mathrm{C} 2-\mathrm{C} 1$ & 130.8 & 130.1 \\
\hline C3-C2-H2 & 117.5 & 115 \\
\hline $\mathrm{C} 1-\mathrm{C} 2-\mathrm{H} 2$ & 116.7 & 115 \\
\hline $\mathrm{C} 2-\mathrm{C} 3-\mathrm{C} 4$ & 132.5 & 130.7 \\
\hline $\mathrm{C} 2-\mathrm{C} 3-\mathrm{H} 3$ & 114.8 & 114.6 \\
\hline $\mathrm{C} 4-\mathrm{C} 3-\mathrm{H} 3$ & 112.7 & 114.6 \\
\hline $\mathrm{O} 3-\mathrm{C} 4-\mathrm{O} 4$ & 121.3 & 121.4 \\
\hline $\mathrm{O} 3-\mathrm{C} 4-\mathrm{C} 3$ & 118.4 & 118.5 \\
\hline $\mathrm{O} 4-\mathrm{C} 4-\mathrm{C} 3$ & 120.2 & 120.1 \\
\hline $\mathrm{C} 1-\mathrm{O} 1-\mathrm{Zn}$ & 130.1 & 127.2 \\
\hline C4-O4-H4 & 110.7 & 109.5 \\
\hline $\mathrm{Zn}-\mathrm{O} 5-\mathrm{H} 5 \mathrm{~A}$ & 121.8 & 120 \\
\hline Zn-O5-H5B & 117 & 119 \\
\hline $\mathrm{Zn}-\mathrm{O6}-\mathrm{H} 6 \mathrm{~A}$ & 118.2 & 117.6 \\
\hline Zn-O6-H6B & 105.8 & 106.4 \\
\hline
\end{tabular}

is over $\mathrm{Zn}$, while the negative sites are partially over O3. Positive and negative sites are spread over O2, O4, C5, C6 and O16. In LUMO, the negative and positive sites are observed over $\mathrm{O} 14$, $\mathrm{O} 15, \mathrm{O} 4$, while the groups of $(\mathrm{C} 7, \mathrm{C} 8, \mathrm{H} 12)$ and
(C5, C6, H11) are partially covered with positive and negative sites. The more highly conjugated the system, the smaller HOMO-LUMO gap [29, 30]. Gauss-Sum 2.2 Program [31] is used to calculate group contributions to the molecular orbitals and prepare the density of the state DOS as shown in Fig. 8. The DOS spectrum is created by convoluting the molecular orbital information with the gaussian contour of the unit height. To ascertain the optical properties of the crystal, the values of optical constants have been determined from the recorded UV-Vis absorption spectrum as: extinction coefficient $\mathrm{K}=65.52$, reflectance $\mathrm{R}=1.98$ and refractive index $\mathrm{n}=1.3$, computed using standard formula [32]. The energy gap calculated by the B3LYP method is found to be $3.2613 \mathrm{eV}$ which agrees with the energy gap calculated by the Tauc model, i.e. $3.74 \mathrm{eV}$ as shown in Fig. 9 [33].

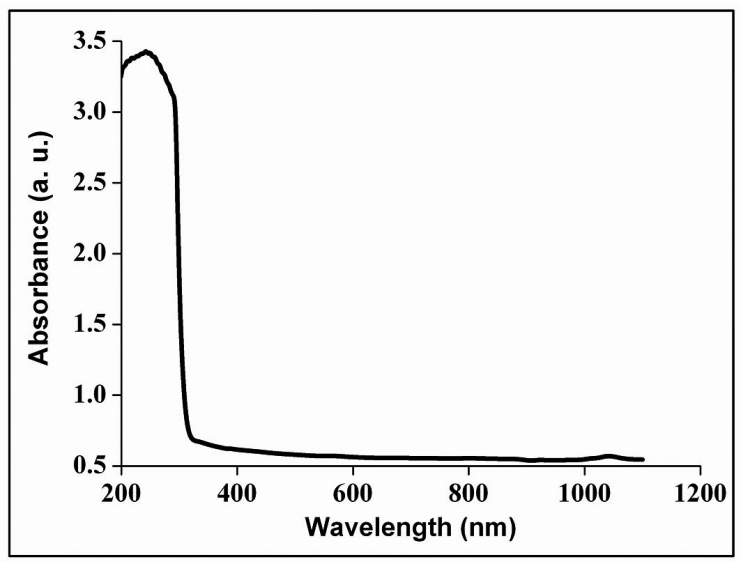

Fig. 6. UV-Vis spectrum of ZHMD crystal.

\subsection{Mulliken and Natural Population Analysis}

Population analysis is an investigation of charge distribution within molecules. Mulliken population analysis MPA is established as the linear combination of atomic orbitals and therefore the wave function of the molecule [34]. The Natural Population Analysis NPA is different from conventional MPA and seems to exhibit improved numerical stability. It illustrates the electron distribution in compounds. NPA analysis has been carried out using B3LYP basis, and the results are compared with 
Table 3. Detailed assignment of observed and calculated vibrational frequencies of ZHMD along with potential energy distribution.

\begin{tabular}{|c|c|c|c|c|}
\hline \multicolumn{4}{|c|}{$\begin{array}{l}\text { Experimental frequency }\left[\mathrm{cm}^{-1}\right] \text { Calculated wavenumber }\left[\mathrm{cm}^{-1}\right] \\
\text { B3LYP } 6 /-311++\mathrm{G}(\mathrm{d}, \mathrm{p})\end{array}$} & \multirow[t]{2}{*}{ Vibrational assignments with PED \% } \\
\hline \multirow{2}{*}{$\frac{\text { FT-IR }}{3773}$} & \multirow[t]{2}{*}{ FT-Raman } & \multirow{2}{*}{$\frac{\text { FT-IR }}{3762}$} & Veda & \\
\hline & & & 3762 & $\mathrm{OH} v(99 \%)$ \\
\hline \multirow[t]{7}{*}{3386} & 3245 & 3226 & 3225 & $\mathrm{OH} v(92 \%)$ \\
\hline & 3053 & 3078 & 3077 & $\mathrm{OH} v(92 \%)$ \\
\hline & 2462 & 1800 & 1800 & OC $v(78 \%)$ \\
\hline & 2257 & 1680 & 1681 & $\mathrm{CC} v(20 \%)+\mathrm{HOH} b(54 \%)$ \\
\hline & 2039 & 1678 & 1678 & $\mathrm{CC} v(51)+\mathrm{HOH} b(17 \%)$ \\
\hline & 1812 & 1647 & 1647 & $\mathrm{HOH} \mathrm{b}(73 \%)$ \\
\hline & 1703 & 1594 & 1594 & OC $v(82 \%)$ \\
\hline \multirow[t]{3}{*}{1505} & 1609 & 1504 & 1504 & $\mathrm{HOC} \mathrm{b}(74 \%)$ \\
\hline & 1397 & 1433 & 1433 & $\mathrm{OC} v(11 \%)+\mathrm{CC} v(34 \%)+\mathrm{HCC} \mathrm{b}(36 \%)$ \\
\hline & 1227 & 1368 & 1368 & $\mathrm{OC} v(24 \%)+\mathrm{HCC} b(55 \%)$ \\
\hline \multirow[t]{3}{*}{1193} & & 1222 & 1222 & $\mathrm{OC} v(23 \%)+\mathrm{HCC} b(59 \%)$ \\
\hline & 1001 & 1042 & 1042 & $\mathrm{HCCC} t(37 \%)+\mathrm{HCCO} t(52 \%)$ \\
\hline & 899 & 891 & 891 & HOCC t $(65 \%)+$ OCOC out $(11 \%)$ \\
\hline \multirow[t]{2}{*}{863} & & 867 & 867 & $\mathrm{OC} v(15 \%)+\mathrm{CCv}(14 \%)+\mathrm{OCC} b(27 \%)$ \\
\hline & 800 & 803 & 803 & $\mathrm{CC} v(16 \%)+\mathrm{OCO} b(23 \%)+\mathrm{OCC} b(10 \%)+\mathrm{CCO} b(10 \%)$ \\
\hline 714 & & 798 & 798 & CCCC t $(16 \%)+$ OCOC out $(52 \%)$ \\
\hline \multirow[t]{4}{*}{573} & & 575 & 505 & $\mathrm{HOH} b(13 \%)+\mathrm{HOZnO} \mathrm{t}(68 \%)$ \\
\hline & 377 & 394 & 358 & $\mathrm{CCC} b(27 \%)+\operatorname{COZn} b(21 \%)+\mathrm{OCC} b(15 \%)$ \\
\hline & 303 & 309 & 291 & $\mathrm{ZnO} v(11 \%)+\mathrm{HOZnOt}(21 \%)+\mathrm{CCCC} t(33 \%)$ \\
\hline & 80 & 85 & 80 & $\mathrm{COZn} b(25 \%)+\mathrm{OZnO} b(13 \%)+\mathrm{CCOZn}$ out $(25 \%)$ \\
\hline
\end{tabular}

$v=$ stretching, $\mathrm{b}=$ bending, $\gamma=$ out of plane bending, $\mathrm{t}=$ torsion

that of Mulliken analysis. Corresponding pictorial charge distribution is given in Fig. 10.

\subsection{Thermal studies}

The TGA and DTA traces of ZHMD are shown in Fig. 11. To determine the stability of the grown crystal, TGA has been recorded at a scanning rate of $20{ }^{\circ} \mathrm{C} / \mathrm{min}$ from $50{ }^{\circ} \mathrm{C}$ to $800{ }^{\circ} \mathrm{C}$. It is seen that the crystal is thermally stable up to $150{ }^{\circ} \mathrm{C}$. Decomposition of ZHMD occurs in three stages involving dehydration and decomposition. The first weight loss of $49.8 \%$ is due to the decomposition of maleic acid, the second weight loss of $7.48 \%$ occurs due to decomposition of zinc acetate and the third weight loss of $11.74 \%$ is due to the residue.

\subsection{Thermodynamic properties}

The statistical thermochemical analysis of ZHMD is performed considering the molecule to be at room temperature and upon atmospheric pressure. Thermodynamic properties such as zero point energy, rotational constants, rotational temperatures, molar capacity, energy and entropy of ZHMD calculated using B3LYP/6-311++G(d,p) basis set are listed in Table 5. From the theoretical harmonic frequencies obtained by B3LYP method in the temperature range of $100 \mathrm{~K}$ to $1000 \mathrm{~K}$, the thermodynamic functions such as entropy $\mathrm{S}$, specific heat capacity at constant pressure $\mathrm{C}_{\mathrm{p}}$ and enthalpy change $\Delta \mathrm{H}$ for the title compound are evaluated and for example at $100 \mathrm{~K}$ the values are $663.74 \mathrm{~J} / \mathrm{mol} \cdot \mathrm{K}, 218.98 \mathrm{~J} / \mathrm{mol} \cdot \mathrm{K}$ 


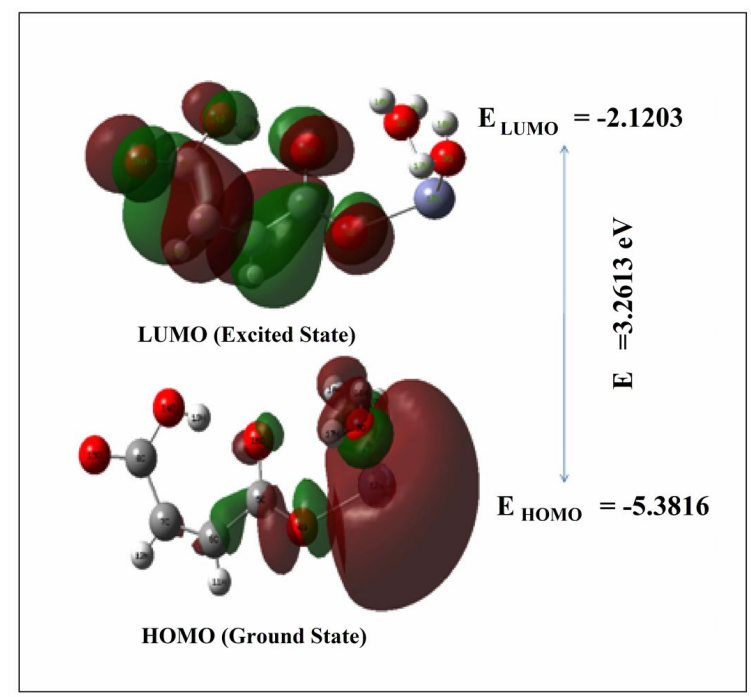

Fig. 7. Molecular orbitals and energies for the HOMO and LUMO of ZHMD.

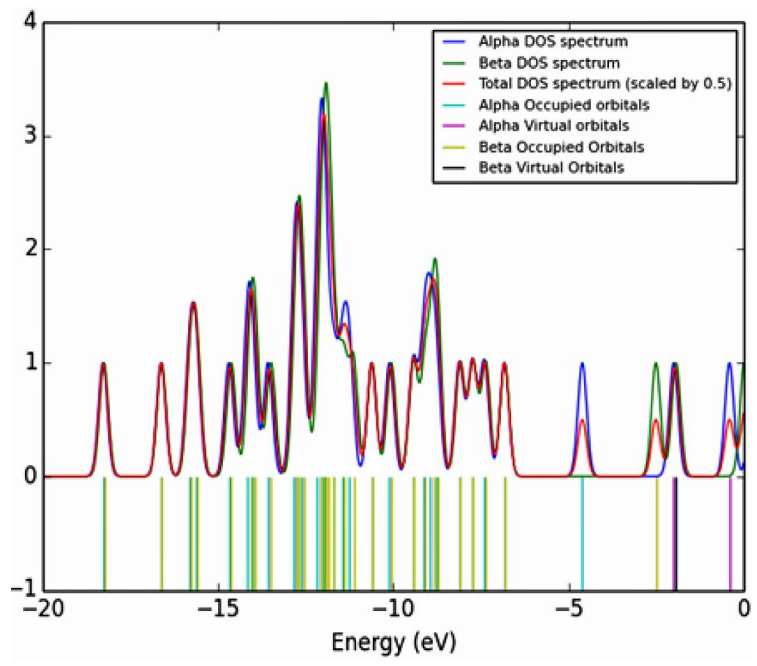

Fig. 8. DOS spectrum of ZHMD.

and $164.14 \mathrm{~kJ} / \mathrm{mol} \cdot \mathrm{K}$, respectively. With the increase in temperature, the thermodynamic properties are observed to increase due to the fact that the vibrational intensities of molecules increase with temperature $[35,36]$. The best fit between the two, viz. thermodynamic properties and temperature is established by the quadratic formula and the corresponding correlation graphs are given in Fig. 12.

$$
\begin{gathered}
S=262.84+0.6526 T-2.573 \times 10^{-4} T^{2} \\
R^{2}=0.9998
\end{gathered}
$$

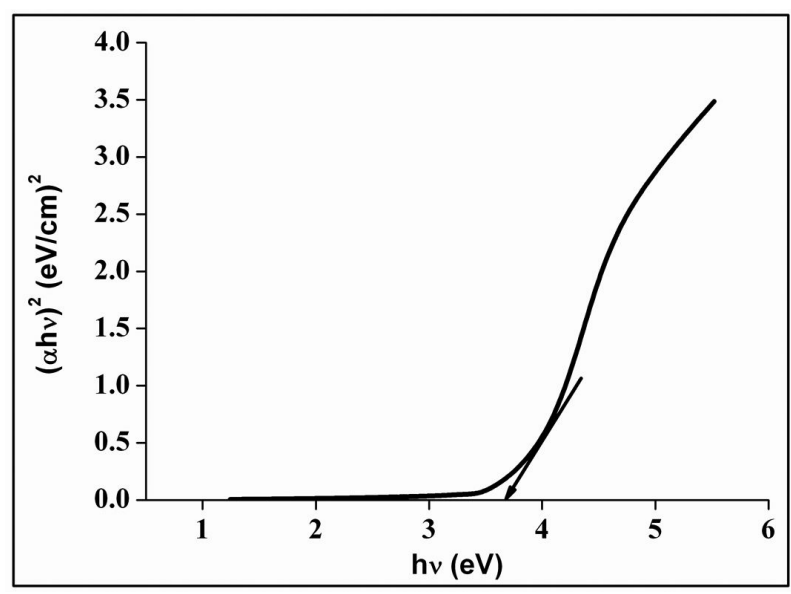

Fig. 9. Tauc plot of ZHMD crystal.

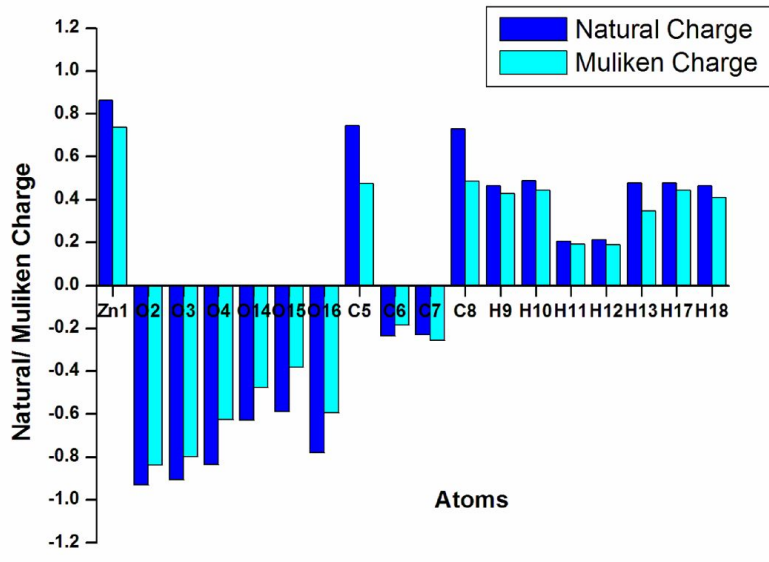

Fig. 10. Plot of Mulliken charges obtained by B3LYP/$311++\mathrm{G}(\mathrm{d}, \mathrm{p})$ methods.

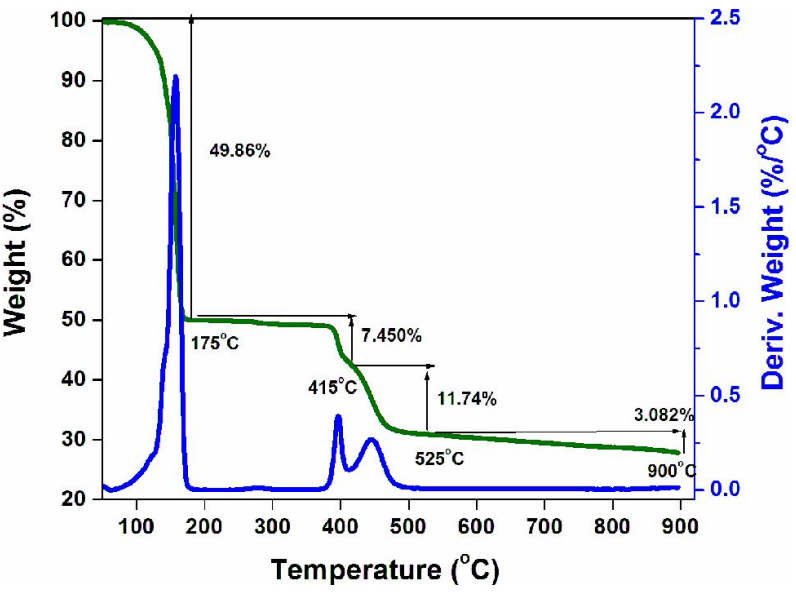

Fig. 11. TG-DTA graph of ZHMD crystal. 


$$
\begin{gathered}
C_{p}=59.34+0.331 T-1.7463 \times 10^{-4} T^{2} \\
R^{2}=0.9999 \\
\Delta H=-7.433+0.1069 T+6.5 \times 10^{-5} T^{2} \\
R^{2}=0.9998
\end{gathered}
$$

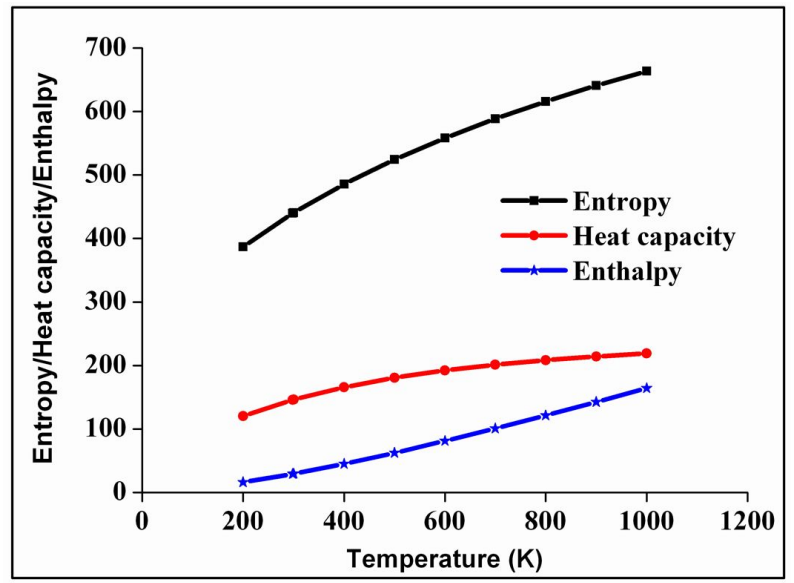

Fig. 12. Correlation graph between entropy, heat capacity and enthalpy with temperature.

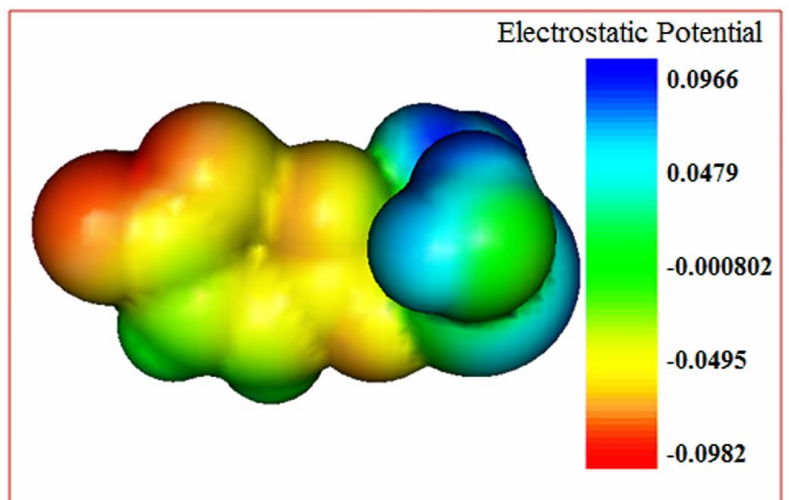

Fig. 13. The molecular electrostatic potential surface of ZHMD single crystal.

\subsection{First order hyperpolarizability}

Nonlinear optics NLO is the branch of optics that elucidates the behavior of light in nonlinear media. The dielectric polarization $\mathrm{P}$ behaves nonlinearly in the electric field $\mathrm{E}$ of the light. The second, third order and even higher harmonics are obtained by multiplying the fundamental frequency with the induced polarization. The hyperpolarizability is a third rank tensor characterized by $3 \times 3 \times 3$ matrix. The 27 components of the $3 \mathrm{D}$ matrix can be reduced to 10 components by Kleinman symmetry [37]. The first order hyperpolarizability $\beta$ of the molecule along with related properties calculated using B3LYP method is presented in Table 6. It follows from the table that the values of dipole moment and hyperpolarizability are greater than those of urea. Hence, it is concluded that the ZHMD single crystal has better nonlinear properties.

\subsection{Natural Bond Orbital Analysis}

NBO analysis is a useful tool to get an intuitive description of both electron orbital and population analysis [38]. Using the $6-311++G(d, p)$ basis, a second order perturbation theory study of Fock matrix in NBO basis is performed, which outlines the interaction between various molecular orbitals. Normally, these interactions are between bonding NBOs and non-bonding or antibonding orbitals. From the calculated values of $\mathrm{E}^{2}$, which correspond to the energy of hyper conjugative interaction, it is noted that for the interactive $\mathrm{C} 8-\mathrm{O} 15$ and $\mathrm{C} 6-\mathrm{C} 7$, the values are notable. The $\mathrm{E}^{2}$ values are $29.03 \mathrm{~kJ} / \mathrm{mol}$ and $37.22 \mathrm{~kJ} / \mathrm{mol}$, respectively. The larger the value of $\mathrm{E}^{2}$, the more intense is the interaction among electron donors and electron acceptors. Hence, there exists an intermolecular hyper conjugative interaction between $\Pi(\mathrm{C} 6-\mathrm{C} 7)$ and $\Pi \cdot(\mathrm{C} 8-\mathrm{O} 15)$. The ZHMD structure is stabilized by these interactions.

\subsection{Molecular Electrostatic Potential}

The molecular electrostatic potential MEP of a ZHMD molecule is a good guide to assess the molecule reactivity approaching positively or negatively charged reactants [39-41]. Mapping of the MEP on the molecular surface is performed with Gauss view shown in Fig. 13. It is seen in the MEP that the portions of positive potential are over all the hydrogen atoms (blue), while the negative potential sites are over the oxygen atoms (red). The green color represents zero electrostatic potential 
Table 4. Experimental and calculated absorption wavelength $\lambda$, excitation state, oscillator strength [f], electronic absorption value $[\mathrm{eV}]$ and transition of ZHMD by TD-DFT method.

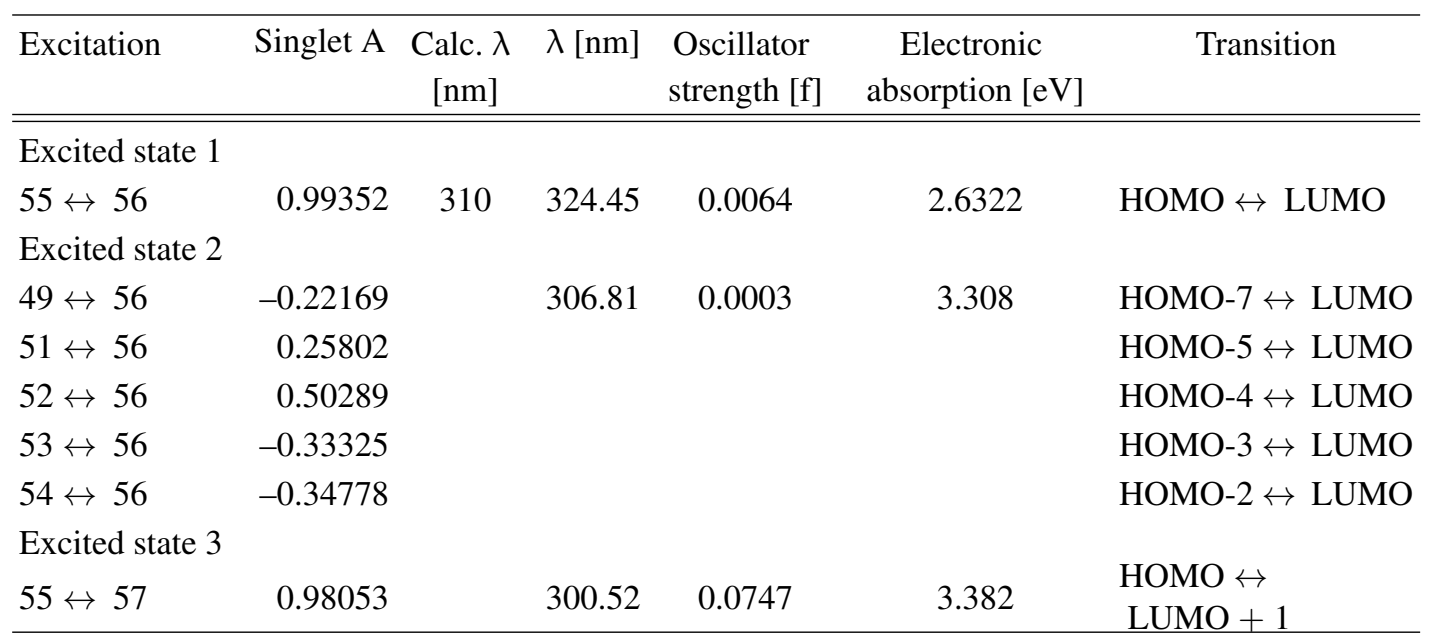

Table 5. Calculated thermodynamic parameters of ZHMD crystal.

\begin{tabular}{lc}
\hline Parameter & B3LYP/6-311++G(d,p) \\
\hline \hline Zero point vibrational energy [kcal/mol] & 83.58763 \\
Rotational constant [GHz] & 2.10526 \\
& 0.34084 \\
& 0.34336 \\
Rotational temperatures [K] & 0.09672 \\
& 0.01636 \\
Entropy [cal/mol·K] & 0.01552 \\
Molar capacity at constant volume $[\mathrm{cal} / \mathrm{mol} \cdot \mathrm{K}]$ & 105.111 \\
Energy [kcal/mol] & 32.891 \\
\end{tabular}

which is on the carbon atoms. The MEP, thus, simultaneously displays molecular size as well as positive, negative and neutral electrostatic regions of the title molecule. The colors seen in MEP confirm that intermolecular interaction can occur in the crystal.

\subsection{Global reactivity descriptors}

The overall stability of the system is assessed by measuring the global reactivity descriptors. The global electrophilicity index $\omega$ introduced by Parr [42, 43] is calculated using electronic potential $\mu$ and chemical hardness $\eta$. The values of ionization potential $\mu$, chemical hardness $\eta$, softness S, electronegativity $\chi$ and electrophilicity ratio $\omega$ are $-3.7509,1.6306,0.3066,3.7509$ and 4.314 , respectively. The value of $\mu$ indicates that the grown crystal is a soft molecule, hence, more easily polarizable.

\section{Third order nonlinear optical properties}

The Z-scan is a successful technique to study the third order NLO properties namely the nonlinear refractive index $\mathrm{n}_{2}$, nonlinear absorption coefficient $\beta$ and the third order susceptibility $\chi^{3}$. Fig. 14 and Fig. 15, show the normalized transmission at the open and closed aperture. The transmission near the focus indicates 
Table 6. Electric dipole $\mu$, polarizability $\alpha$, hyperpolarizalibility $\beta$ of ZHMD crystal.

\begin{tabular}{cccc}
\hline Parameter & esu $\left(\times 10^{-24}\right)$ & Parameter & esu $\left(\times 10^{-33}\right)$ \\
\hline \hline$\alpha_{\mathrm{xx}}$ & 14.1291 & $\beta_{\mathrm{xxx}}$ & -501.0506 \\
$\alpha_{\mathrm{xy}}$ & -0.5216 & $\beta_{\mathrm{xxy}}$ & 78.6149 \\
$\alpha_{\mathrm{yy}}$ & 14.480 & $\beta_{\mathrm{xyy}}$ & -118.213 \\
$\alpha_{\mathrm{xz}}$ & 3.0744 & $\beta_{\mathrm{yyy}}$ & 195.7825 \\
$\alpha_{\mathrm{yz}}$ & 2.0548 & $\beta_{\mathrm{xxz}}$ & -162.4525 \\
$\alpha_{\mathrm{zz}}$ & 20.8813 & $\beta_{\mathrm{xyz}}$ & 57.0286 \\
$\alpha_{\mathrm{tot}}$ & 16.4971 & $\beta_{\mathrm{yyz}}$ & -80.5841 \\
$\Delta \alpha$ & 25.3422 & $\beta_{\mathrm{xzz}}$ & -277.7643 \\
$\mu_{\mathrm{x}}$ & -0.2471 & $\beta_{\mathrm{yzz}}$ & 37.5131 \\
$\mu_{\mathrm{y}}$ & -0.0018 & $\beta_{\mathrm{zzz}}$ & -624.7585 \\
$\mu_{\mathrm{z}}$ & -0.4226 & $\beta_{\text {tot }}$ & 1286.4736 \\
$\mu$ & 0.4895 & & \\
\hline
\end{tabular}

the nonlinear absorption, which is regarded as two-photon absorption. As seen from the closed aperture Z-scan curve, the prefocal transmittance peak is followed by the post focal valley which suggests that the origin of the nonlinear refractive index is thermo-optic. The nonlinear parameters are determined for ZHMD crystal using the standard relationships formulated by Sheik-Bahae et al. [44]. The nonlinear absorption coefficient $\beta=0.5594 \times 10^{-3} \mathrm{~cm} / \mathrm{W}$ and the value of third order nonlinear susceptibility $x^{3}=3.0369 \times 10^{-7}$ esu. The nonlinear refractive index of the grown crystal is $-9.4799 \times 10^{-9} \mathrm{~cm}^{2} / \mathrm{W}$. The value is negative which indicates that the lensing effect is of defocusing nature. The defocusing nature and twophoton absorption coefficient are essential for the construction of intense laser beams and also useful in night vision devices.

\section{Conclusions}

A transparent, optical quality, colorless single crystal of ZHMD is grown using slow evaporation solution growth technique. A detailed vibrational assignment has been made for the ZHMD crystal using FT-IR and FT-Raman spectra. The observed and simulated spectra agree well with good frequency fit by the DFT (B3LYP) method.

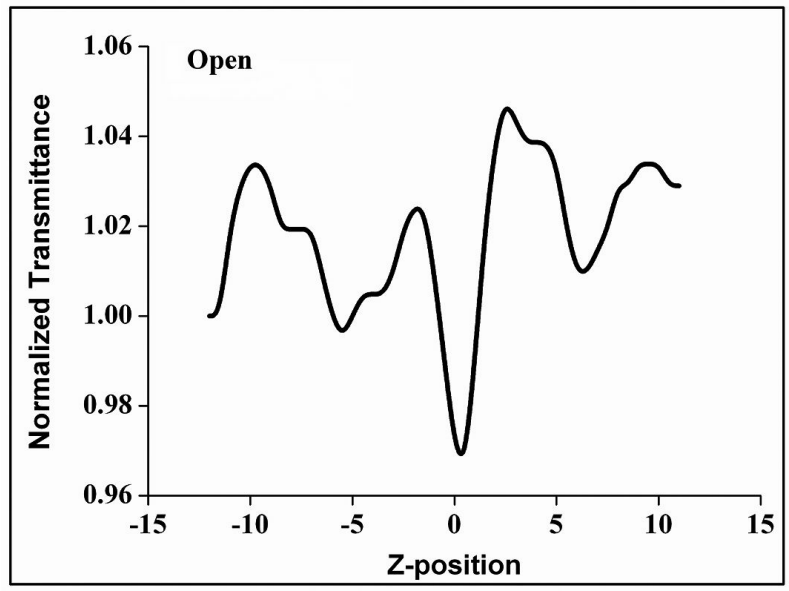

Fig. 14. Open aperture curve of ZHMD crystal.

The optical absorption in the entire visible region of the UV-Vis spectrum is flat and constant which suggests that the crystal is suitable for NLO applications. The optical parameters, such as extinction coefficient, reflectance and refractive index are determined. The HOMO-LUMO energy gap asserts the chemical reactivity of the molecule. Stability of the molecule proceeding from hyper-conjugative interaction and charge delocalization is confirmed using NBO analysis. NPA and MPA electron distribution in the compound is obtained. The MEP map of the crystal shows that the crystal has negative potential sites on oxygen and positive 
potential sites around hydrogen. Thermodynamic parameters such as heat capacity, entropy and enthalpy are determined. From TGA it is seen that the crystal is thermally stable up to $150{ }^{\circ} \mathrm{C}$, which suggests that it is suitable for device applications. The DFT calculations provide valuable insight into geometrical parameters, vibrational energies, rotational constant, thermodynamic properties, thermal energies, entropy, molar capacity constant and NLO activity of the compound. The calculated result obtained by DFT shows that the optimized geometry can well reproduce the crystal structure. The third order nonlinear properties of ZHMD crystal are confirmed by Z-scan technique, showing the crystal suitability for nonlinear optical devices.

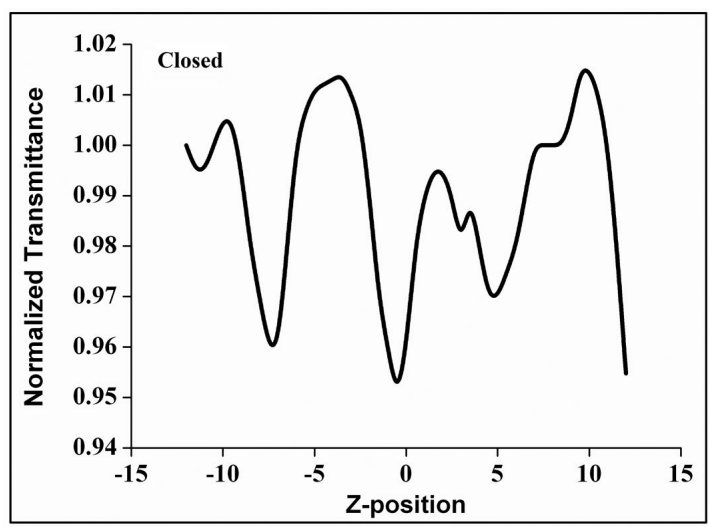

Fig. 15. Closed aperture curve of ZHMD crystal.

\section{Acknowledgements}

The authors of this manuscript would like to thank SAIF, IIT, Madras, for their technical support and for Z-scan measurement NIT, Trichy.

\section{References}

[1] TAdashi A., AKIRA K., Thermochim. Acta, 400 (2003), 175.

[2] Balakrishnan T., Ramamurthi K., Cryst. Res. Technol., 41 (2006), 1184.

[3] Koleva V., Stollova D., J. Mol. Struct., 611 (2002), 1.

[4] Narayana P.A., Venkateswarlu P., J. Chem. Phys., 53 (1970), 281.

[5] RAJALAKSHMI M., INDIRAJITH R., PALANICHAMY M., GOPALAKRISHNAN R., Spectrochim. Acta A, 84 (2011), 43.

[6] Karuna S., Balu A.R., Shyamala D., NAgarethinam V.S., Delci Z., Int. J. Adv. Chem.Sci. Appl., 3 (2015), 32.
[7] Rios M.A., Rodriguez J., Can. J. Chem., 71 (1993), 303.

[8] KarabacaK M., Kurt M., Spectrochim. Acta A, 71 (2008), 876.

[9] JAMROZ M.H., Vibrational energy distribution analysis VEDA 4 Computer program, Warsaw, Poland, 2004.

[10] Dennington R.I., Keith T., Millam J., Eppinnett K., Hovell W., Gilliland R., Gauss View Version 3.09, Semichem Inc. Shawnee Mission, KS, USA, 2003.

[11] Lee C., Yang W., Parr R.G., Phys. Rev. B, 37 (1988), 785.

[12] Becke A.D., J. Chem. Phys., 98 (1993), 5648.

[13] Choo J., Kim S., Joo H., Kwon Y., J. Mol. Struct. Theochem., 587 (2002), 1.

[14] Choi C.H., Kertesz M., J. Phys. Chem. A, 101 (1997), 3823.

[15] Sutton L.E., Tables of Interatomic Distance and Configuration in Molecules and Ions, Chemical Society, Burlington House, 1959.

[16] Muthu S., Ramachandran G., UmamahESWARI J., Spectrochim. Acta A, 93 (2012), 214.

[17] Sarojini K., Krishnan H., KanaKaM C.C. Muthu S., Spectrochim. Acta A, 108 (2013), 159.

[18] Jonepradeepa S., Sundaraganesan N., Spectrochim. Acta A, 125 (2014), 211.

[19] Sathyanarayana D.N., Vibrational Spectroscopy Theory and Applications, $2^{\text {nd }}$ Ed, New Generation International Limited Publishers, New Delhi, 2004.

[20] Delci Z., Shyamala D., Karuna S., Senthil A., Thay umanavan A., Int. J. Chem. Tech. Res., 4 (2012), 816

[21] Sajan D., Hubert J.I., JaYAKUMARN V.S., ZALESKI J., J. Mol. Struct., 785 (2006), 43.

[22] Delci Z., Shyamala D., Karuna S., Senthil A., Thayumanavan A., Indian J. Pure Appl. Phy., 51 (2013), 426.

[23] Sundius T., Vib. Spectrosc., 29 (2002), 89

[24] Rastogi V.K., Palafox M.A., Tanwar R.P., MitTAL L., Spectrochim. Acta A, 58 (2002), 1987.

[25] Silverstein M., Basseler G.C., Morill C., Spectrometric Identification of Organic Compounds, Wiley, New York, 1981.

[26] RaO C.N.R., Ultraviolet and Visible Spectroscopy Chemical Applications, Plenum Press, New York, 1975.

[27] Kosar B., AlbayraK C., Spectrochim. Acta A, 78 (2011), 160.

[28] Jacquemin D., Preat J., Perpete E.A., Chem. Phys. Lett., 40 (2005), 254.

[29] Ataly Y., Avci D., Basoglu A., J. Struct. Chem., 19 (2008), 239.

[30] ViJayakumar T., Joe I.H., NaIR C., JayaKUMAR V., J. Chem. Phys., 343 (2008), 83.

[31] Rajesh P., Gunasekaran S., Sesshadri S., Gnanasambandan T., Spectrochim. Acta A, 132 (2014), 249. 
[32] Sabari G.T.C., Dhanuskodi S., Cryst. Res. Technol., 12 (2009), 1297.

[33] Shyamala D., Rathikha R., Gomathi K., Int. $J$. Eng. Res. Appl., 6 (2016), 42.

[34] Renuga D.T.S., Sharmikumar J., Ramkumaar G.R., Spectrochim. Acta A, 137 (2015), 761.

[35] Delci Z., Shyamala D., Vigneshwaran S., Thayumanavan A., J. Optoelectron. Adv. M., 16 (2014), 826.

[36] Helgaker T.U., Jensen H.J.A., Jorgensen P., J. Chem. Phys., 84 (1986), 6280.

[37] Kleinman D.A., Phys. Rev B, 126 (1962), 1977.

[38] Golcuk K., Altun A., Kumru M., Spectrochim. Acta A, 59 (2003), 1841.

[39] Choi C.H., Kertesz M., J. Chem. Phys., 108 (1998), 66.
[40] Hasan Tanak., Yavuz Koysall., Samil IsiK., Hanifi Yaman., Vefa Ahsen., B. Korean Chem Soc., 32 (2011), 673.

[41] Luque F.J., Lopez J.M., Orozco M., Theor. Chem. Acc., 103 (2000), 343.

[42] Parr R.G., Pearson R.G., J. Am. Chem. Soc., 105 (1983), 7512.

[43] Parr R.G., Szentpaly L., Liu S., J. Am. Chem. Soc., 121 (1999), 1922.

[44] Sheik-Bahae M., Said A.A., Wei T.H., Hagan D.J., StRYland VAN E.W., IEEE J. Quantum Elect., 26 (1990), 760.
Received 2017-01-19

Accepted 2017-10-19 